\title{
Predictors of violent behaviours in young adults dating relationships
}

\author{
Sesar Kristina ${ }^{1, ~ *}$, Dodaj Arta ${ }^{2}$, Simic Nataša $^{3}$, Barisic Marijana ${ }^{2}$ \\ ${ }^{1}$ Centre of Mental Health, Široki Brijeg Health Care Centre, Bosnia and Herzegovina \\ ${ }^{2}$ Department of Psychology, University of Mostar, Mostar, Bosnia and Herzegovina \\ ${ }^{3}$ Department of Psychology, University of Zadar, Zadar, Croatia
}

\section{Email address:}

ksesar@gmail.com (K. Sesar)

\section{To cite this article:}

Sesar Kristina, Dodaj Arta, Simic Nataša, Barisic Marijana. Predictors of Violent Behaviours in Young Adults Dating Relationships. Psychology and Behavioral Sciences. Vol. 2, No. 6, 2014, pp. 233-242. doi: 10.11648/j.pbs.20140306.18

\begin{abstract}
The aim of this study was to examine the prevalence of dating violence and jealousy among university students. The role of situational and background factors of risk in explaining violent behaviour was examined. The study included 33 men and 89 women participants, from 20 to 24 years of age, from the Faculty of Philosophy at the University of Mostar. For the assessment of dating violence, The Revised Conflict Tactics Scales (CTS2) Partner-to-Partner was used. Males and females estimated the intensity of their jealousy in hypothetical situations presenting scenarios of emotional and sexual infidelity. The results of the analyses of the total sample showed that boys and girls differ significantly with respect to the frequency of committing and exposure to violent behaviour in a dating relationship. Men were more often the perpetrators of sexual abuse and threatening behaviour in relation to women. At the same time they were more often exposed to various forms of examined abuse in comparison to women. No differences in the intensity of jealousy between men and women were found. However, a regression analysis showed that jealousy, as a contextual variable, and earlier violent behaviour, as well as a situational variable, is a significant predictor of the exposure and perpetration of dating violence. The results of this study should be taken into account in the development and implementation of programmes for the prevention of violent behaviour in youth adults dating relationships.
\end{abstract}

Keywords: Jealousy, Dating Violence, Gender Differences, Risk Factors

\section{Introduction}

Adolescence is period where young people begin to form and maintain dating relationships. Recent research documented the significant occurrence of violence in adolescent dating relationships (1-2). The wide variety of forms, function, frequency as well as the manifestation of violent behaviour causes for there to be variability in the definition of violence. The term adolescent dating violence is often described in the context of stable emotional relationships, which characterize threats or physical, sexual and psychological harm inflicted by a current intimate partner (3-4). However, some authors suggest that these relationships do not necessarily need to be stable. Indeed it can refer to one-time dating (5).

A consensus is evident in the literature that adolescent dating abuse includes three forms, psychological, physical and sexual abuse. Psychological abuse encompasses a broad array of unphysical behaviours, whose effect is to cause emotional damage or fear on a partner. Such abuse may include humiliating, underestimating, embarrassing and controlling a partner (6). Other commons forms of such abuse are isolating the victim from friends and family as well as denying the victim access to money or other basic resources (6). Physical dating violence includes activities of physical force such as slapping, hitting, pushing with the intention, or perceived intention, of causing physical pain or injury to a partner (7). Sexual abuse refers to undesired sexual behaviour without a person's consent or forcing that person physically (4). Experience with dating violence may occur in a relationship with one partner, as well as during dating periods with various partners. During the experience of violence, different subtypes of abuse, for example physical abuse, psychological aggression or threats can occur in conjunction. The results shows that victims of dating violence are often exposed to multiple forms of violence 
from a partner (8-15). Research studies have also found a significant relationship between physical abuse and psychological aggression (16-17). Murphy and O'Leary (18) emphasize psychological aggression as a significant predictor of physical abuse, while exposure to physical and psychological abuse predicts sexual abuse (19). Frieze (20) confirmed the existence of a significant relationship between physical and sexual abuse. Studies involving women as participants indicated a statistically significant correlation between physical, sexual, psychological and verbal abuse (21). Similar results were obtained by Straus et al. (22), who reported a significant intercorrelation between psychological aggression, physical and sexual abuse. These findings suggest a significant overlap between different subtypes of violence, which implicate that exposure to one type of violence, is rare.

Several studies have found that a lot of partner violence is reciprocal or that very often victims of violent behaviour are or become perpetrators of violence $(17,23-27)$. With respect to dating violence, three profiles can be distinguished: victims, perpetrators and victims/perpetrators of dating violence (28). Partners with reciprocal violence are perpetrators of severe forms of violence. Furthermore, they are more often violent toward their partner compared to those who are only victims or perpetrators of dating violence (29).

A considerable body of research indicates a different prevalence rate of dating violence (30). Rates of dating violence using a stricter definition of dating violence, such as physical and/or sexual abuse that causes injury, ranged from $10 \%$ to $20 \%$ regarding those adolescents exposed to violence in dating relationships (31). Studies using a wider definition of dating violence which included psychological abuse reported the prevalence of violence at about $50 \%$ (31). No consensus has emerged regarding the rates of violent behaviour by gender. Numerous studies finds different rates of perpetration by gender, which are not in accordance with public perception of the higher perpetration of violence by males and the higher prevalence of females as victims of violence (26). So far, the studies conducted suggest that there are no gender differences in the rates of exposure to psychological and physical violence (32). However, studies note higher rates of female perpetration in psychological and physical violence, compared to men (32). With respect to severe types of physical violence among gender, the obtained results are not consistent. For example, some studies suggest that females are more often victims of severe forms of violence (9), while some others suggest that men are prone to be victims of more serious forms of violence (33-34). Other studies emphasize similar levels of victimization reported by males and females (35).

Since previously conducted studies have found a relationship between dating violence and mental health (36), it seems relevant to investigate the prevalence of dating violence among young people as well as to reveal the causes of such behaviour. Findings suggest that the most important risk factor for inflicting and sustaining dating violence is jealousy (37-38).
Jealousy is defined as a set of affective, behavioural, and cognitive responses that occurs when the existence and/or quality of a person's relationship is in realistic or imaginary terms threatened by a third party (39). It can lead to positive or negative emotions, as well as to different behavioural responses (40-42). According to Smith and Lazarus (43), tendencies toward certain emotional and behavioural responses, as biologically determined behavioural responses, helps people to manage their emotions and adapt to their environment. Tendencies constitute a basic orientation toward a specific emotion (positive or negative), changes in the level of physiological arousal, as well as topics related with the background of a specific emotion (e.g., costs or benefits of the relationship). According to the authors, anger has an innate tendency for attack. The action tendency of fear is avoidance or escape. The clear action tendency for sadness is separation from people who cause a feeling of loss. Finally, guilt is associated with action tendencies such as apologies for damage caused. People usually experience a wide range of emotions at the same time, which lead to the occurrence of different action tendencies (44). Jealous persons can simultaneously feel fear (tendency for avoidance or escape), anger (tendency for attack), as well as other emotions (sadness, guilty), and consequently respond in a different manner (45). In addition to the type of emotions experienced, a significant influence on jealousy is the intensity of the emotional experience (46). A more intense experience of anger, compared to fear, can lead to a higher probability of responding to jealousy by attacking. People who report a more intense emotional experience of jealousy in the form of a negative emotional expression (e.g., showing negative emotion in front of their partner), inappropriate communication patterns (e.g., shouting, threatening their partner) and "other behaviours" (e.g., spying or seeking to control their partner) $(39,41-42)$ are more prone to commit verbal and/or physical abuse toward their partner. Against the background of jealousy, sexual excitement or passion can be a positive as well as a negative emotion (45). Researchers suggest that jealousy based on passion can encourage behaviours such as sexual aggression (47). According to Riggs and O'Leary (48), in the "background-situational" model of aggression, jealousy represents situational factors that increase conflict within a relationship and contribute to violent behaviour. The model postulates that background factors are along situational factors. The authors proposed that the variables of exposure to prior dating violence can be a significant risk factor for committing the same or different type of violent behaviour.

Since a small number of studies investigated the relationship between emotional/sexual jealousy and dating violence, this study tried to investigate this relationship by examining the role of situational and background factors. More specifically, the first aim of the study was to investigate the prevalence rate of dating violence, as well as to test gender differences in committing and exposure to violent behaviour. The second aim of the study was to determine whether emotional and sexual jealousy as a situational risk 
factor, as well as background risk factors (prior exposure to violence by partner) significantly contribute to dating violence.

\section{Methods}

\subsection{Participants}

The study was conducted on a convenience sample of 122 students from the Faculty of Philosophy, University of Mostar. The sample consisted of $33(27 \%)$ males and $89(73 \%)$ females, with an average age of 21.057 ( $\mathrm{SD}=0.432)$. One inclusion criterion for participation in study was that participants had been in an emotional relationship with a member of the opposite sex during the past year or at the time of conducting the study.

\subsection{Instruments}

Dating violence was assessed using the Revised Conflict Tactics Scale (CTS2) Partner-to-Partner $(22,49)$. The scale was designed to measure the range of tactics used in response to conflict with the partner during the past year (49). The 78-item scale (39 behaviours or experiences, each asked once for the respondent and once for the partner) is made up of five subscales: negotiation, psychological aggression, physical assault, sexual coercion and injury. The respondent assesses the frequency with which the acts were used during conflict with a partner in the past year using a 6-point scale ranging from "never" to "20 or more times." There are also response options of "Never in the last year, but did happen before that." and "This has never happened." The time required to complete the questionnaire is seven minutes. There are several methods of scoring the Conflict Tactics Scales. The simplest is to add the response category code values for each scale to create a sum scale. A mean score can also be used as a measure of the distinction between abused and non-abused. Behaviours, or types of behaviours, can also be scored dichotomously as "present" or "not present". Dichotomized scores are used in the calculation of the frequency. Higher scores on the subscales indicate more use of the tactic or of a domain of tactics. The author states that the internal consistency ranges from the .79 to .95 for the subscales (49). A confirmatory factor analysis has not confirmed the original five-factor structure. In our study, five extracted factors were comparable to factors classified as relational abuse, emotional and verbal abuse, threatening behaviour, and sexual and physical violence. The coefficients obtained were in the acceptable range with Cronbach's alpha from .677 to .858 .

In order to test jealousy, the modified Busse method was used (50), which included an assessment of the intensity of jealousy in a hypothetical situation of emotional and sexual infidelity. Participants were instructed to imagine that the person, whom they are in relationship with, was interested in another person. On a scale of seven degrees, where " 0 " meant not jealous, and " 6 " completely jealous, participants were asked to evaluate the degree of jealousy in a situation where the person they were in a relationship with had sexual intercourse with another person, without achieving a deep emotional relationship (the situation of sexual infidelity) and in a situation of deep emotional attachment to another person, without actual sexual intercourse (the situation of emotional infidelity).

\subsection{Procedure}

All participants gave their approval to participate in the study. Questionnaires were applied during regular classes in lecture halls. The average time taken to complete the questionnaires was 15 minutes. After completing the questionnaires, the participants were asked to place them in a box, which was placed at the exit of the lecture hall. The study was accompanied by a form stating the participant's agreement to participate in the study, the consent of authors of the questionnaires to use the study, as well as the Ethics Committee of the Faculty of Philosophy in Mostar.

\section{Statistical Analysis}

The results of 17 participants were excluded from the analysis because of the omission of data on gender (seven participants), as well as because of the incomplete answering of questions related to violent behaviour (10). A statistical analysis was conducted on 122 participants, of which 33 were males and 89 females, ranging in age from 20 to 24 years ( $\mathrm{M}=21.057 ; \mathrm{SD}=0.432)$.

An analysis of the prediction was carried out on the data of students that had been in a dating relationship during the past six months $(\mathrm{N}=85)$.

Scores on all the CTS2 subscales were formed as a simple linear combination. In order to test whether the results have a normal distribution on all the CTS2 subscales, the Kolomogorov-Smirnov test was used. The distribution of the results on the CTS2 subscales was not normal $(\mathrm{p}<0.05)$, which was the reason for the use of non-parametric statistical methods. Regarding the distribution of the results for jealousy, the analysis obtained showed a normal distribution on the scale of sexual, but not on emotional jealousy.

Gender differences in the intensity of emotional jealousy, as well as sexual differences in the frequency of experiencing different forms of adolescent dating violence are tested by the Mann-Whitney U test. Gender differences in the intensity of sexual jealousy are tested with the t-test. Predictors of various types of violence were determined using multiple regression analyses, using the backward method. A statistical analysis was performed using the computer program: StatSoft, Inc., STATISTICA (data analysis software system), version 7.

\section{Results}

Based on the results of the analysis, it was established that 85 participants $(69.672 \%)$ indicated that during the past year or at the time of the study they were in an emotional relationship with a person of the opposite sex.

Gender differences in experiencing dating violence were obtained for verbal abuse, threatening behaviour, sexual 
abuse and physical abuse. Analyses of the results showed that males were more prone to experiencing those types of

violence compared to females (Table 1).

Table 1. Descriptive parameters of exposure to different forms of dating violence with regards to gender of participants

\begin{tabular}{|c|c|c|c|c|c|c|c|c|}
\hline \multirow{2}{*}{ Forms of violent behavior } & \multicolumn{3}{|c|}{ Men } & \multicolumn{3}{|c|}{ Women } & \multirow{2}{*}{$\mathbf{Z}$} & \multirow{2}{*}{$\mathbf{p}$} \\
\hline & $\mathrm{N}(\%)$ & Median & Q3-Q1 & $\mathrm{N}(\%)$ & Median & Q3-Q1 & & \\
\hline Relational violence & $7(21.22)$ & 2.83 & $3.50-1.83$ & $26(29.21)$ & 2.83 & $4.00-1.66$ & 0.32 & 0.746 \\
\hline Emotional and verbal violence & $16(48.48)$ & 1.25 & $2.00-0.37$ & $24(26.96)$ & 0.50 & $1.37-0.12$ & 2.50 & $0.012 * *$ \\
\hline Threatening behaviour & $18(54.54)$ & 0.50 & $1.92-0.00$ & $21(23.59)$ & 0.00 & $0.33-0.00$ & 2.92 & $0.003 * *$ \\
\hline Sexual violence & $17(51.51)$ & 0.75 & $1.37-0.12$ & $22(24.71)$ & 0.00 & $0.62-0.00$ & 3.83 & $0.000 * * *$ \\
\hline Physical violence & $13(39.30)$ & 0.00 & $1.17-0.00$ & $25(28.08)$ & 0.00 & $0.33-0.00$ & 2.50 & $0.012 *$ \\
\hline
\end{tabular}

Note: Q3-Q1quartiles; Z Mann Whitney U test; * $\mathrm{p}<0.05 ; * * \mathrm{p}<0.01 ; * * * \mathrm{p}<0.001$

Statistically significant gender differences were obtained with respect to committing violence against a partner. Males were significantly more likely to be perpetrators of sexual abuse and threatening behaviour than females. With regard to emotional, verbal and physical abuse, gender differences were not obtained (Table 2).

Table 2. Descriptive parameters of perpetration of different forms of dating violence with regards to gender of participants

\begin{tabular}{|c|c|c|c|c|c|c|c|c|}
\hline \multirow{2}{*}{ Forms of violent behavior } & \multicolumn{3}{|c|}{ Men } & \multicolumn{3}{|c|}{ Women } & \multirow{2}{*}{$\mathbf{Z}$} & \multirow{2}{*}{$\mathbf{p}$} \\
\hline & $\mathbf{N}(\%)$ & Median & Q3-Q1 & $\mathbf{N}(\%)$ & Median & Q3-Q1 & & \\
\hline Relational violence & $12(36.36)$ & 3.17 & $4.00-1.00$ & $26(29.21)$ & 3.00 & $4.00-2.00$ & 0.59 & 0.554 \\
\hline Emotional and verbal violence & $17(51.51)$ & 1.50 & $2.62-0.62$ & $24(26.96)$ & 0.75 & $1.50-0.31$ & 1.83 & 0.067 \\
\hline Threatening behaviour & $18(54.54)$ & 0.50 & $1.00-0.00$ & $23(25.84)$ & 0.00 & $0.42-0.00$ & 3.05 & $0.002 * *$ \\
\hline Sexual violence & $21(63.63)$ & 0.57 & $1.43-0.00$ & $20(22.47)$ & 0.00 & $0.00-0.00$ & 3.38 & $0.000 * * *$ \\
\hline Physical violence & $15(45.45)$ & 0.00 & $1.67-0.00$ & $15(16.85)$ & 0.00 & $0.00-0.00$ & 1.90 & 0.057 \\
\hline
\end{tabular}

Note: Q3-Q1quartiles; Z Mann Whitney U test; * $\mathrm{p}<0.05 ; * * \mathrm{p}<0.01 ; * * * \mathrm{p}<0.001$

The average scores and standard deviation of the intensity of jealousy that participants experienced in a hypothetical situation of sexual and emotional infidelity are presented in Table 3. The results showed that there are not statistically significant gender differences in the intensity of jealousy in a hypothetical situation of sexual infidelity $(\mathrm{t}=0.072 ; \mathrm{df}=120$; $\mathrm{p}=0.942)$, as well as a hypothetical situation of emotional infidelity $(\mathrm{Z}=0.322 ; \mathrm{p}=0.746)$.

Table 3. The intensity of jealousy on hypothetical situation of sexual and emotional infidelity regarding to the gender of participants

\begin{tabular}{|c|c|c|c|c|}
\hline \multirow{2}{*}{ Types of infidelity } & \multicolumn{4}{|c|}{ Intensity of jealousy } \\
\hline & Men & Women & $t / Z$ & $\mathbf{p}$ \\
\hline Sexual (M+SD) & $2.71 \pm 1.32$ & $2.69 \pm 1.21$ & 0.07 & $0.942 \dagger$ \\
\hline $\begin{array}{l}\text { Emotional (Mdn; } \\
\text { Q3-Q1) }\end{array}$ & $2.75(4.00-2.00)$ & $3(3.50-2.00)$ & 0.32 & $0.746 \ddagger$ \\
\hline
\end{tabular}

Note: $† \mathrm{t}$-test for independent sample; $\ddagger$ Mann-Whitney U test

In order to assess the predictive contribution to various forms of dating violence, we conducted multiple regression analyses, separately for committing dating violence and exposure to dating violence. Analyses were carried out where the criteria variables in all models were the form of violence (relational violence, physical violence, threatening behaviour, sexual violence, emotional and verbal violence), and the predictor variables were gender, age, other forms of violence and jealousy in hypothetical sexual and emotional infidelity.
Significant regression predictor models for committing violent behaviour are shown in Table 4.

Jealousy in hypothetical sexual infidelity was found to be a significant predictor of relational violence. When it comes to committing physical violence, threatening behaviours and sexual violence explained almost $85 \%$ of the variance of physical violence. Furthermore, emotional, verbal and physical violence were found to be significant predictors of threatening behaviour toward a partner, which together explained almost $82 \%$ of the variance. Sexual violence was found to be a significant predictor of physical violence, which explained $74 \%$ of the variance of the criterion variable.

Predictors of emotional and verbal violence against a partner are found to be threatening behaviour and jealousy in hypothetical sexual infidelity. Significant regression predictor models of experiences of violent behaviour are presented in Table 5. Jealousy in emotional infidelity was found to be a statistically significant predictor of exposure to relational violence. Significant predictors of exposure to physical violence were exposure to threatening behaviour and sexual violence, which together explained almost $74 \%$ of the variance of the criterion variable. When it comes to exposure to threatening behaviour, significant predictors were exposure to emotional, verbal, physical as well as sexual violence. Those predictors together explained $83 \%$ of variance. A significant predictor of exposure to sexual 
violence was found to be exposure to threatening behaviour and physical violence, which together explained $73 \%$ of variance. Furthermore, exposure to threatening behaviour and jealousy in hypothetical sexual infidelity were significant predictors of exposure to emotional and verbal violence.

Table 4. Multiple regression coefficients for predictors of perpetration violence in dating relationship (predictors: gender, ages, committing of other forms of violence, types of infidelity)

\begin{tabular}{|c|c|c|c|c|}
\hline Criterion variable & $\mathbf{R}$ & $\mathbf{R}^{2}$ & Predictors & $\beta$ \\
\hline Relational violence & 0.51 & 0.26 & Sexual infidelity & $0.51 * * *$ \\
\hline Physical violence & 0.92 & 0.85 & $\begin{array}{l}\text { Threatening behaviors } \\
\text { Sexual violence }\end{array}$ & $\begin{array}{l}0.56 * * * \\
0.41 * * *\end{array}$ \\
\hline Threatening behaviors & 0.91 & 0.82 & $\begin{array}{l}\text { Emotional and verbal violence } \\
\text { Physical violence }\end{array}$ & $\begin{array}{l}0.24 * * * \\
0.73 * * *\end{array}$ \\
\hline Emotional and verbal violence & 0.78 & 0.91 & $\begin{array}{l}\text { Threatening behaviors } \\
\text { Sexual infidelity }\end{array}$ & $\begin{array}{l}0.63 * * * \\
0.26 * * *\end{array}$ \\
\hline
\end{tabular}

Note: $\mathrm{R}$ multiple correlation; $\mathrm{R}^{2}$ multiple correlation squared; $\beta$ standardized regression coefficient; $* * * \mathrm{p}<0.001$

Table 5. Multiple regression coefficients for predictors of exposure to violence in dating relationship (predictors: gender, ages, committing of other forms of violence, types of infidelity)

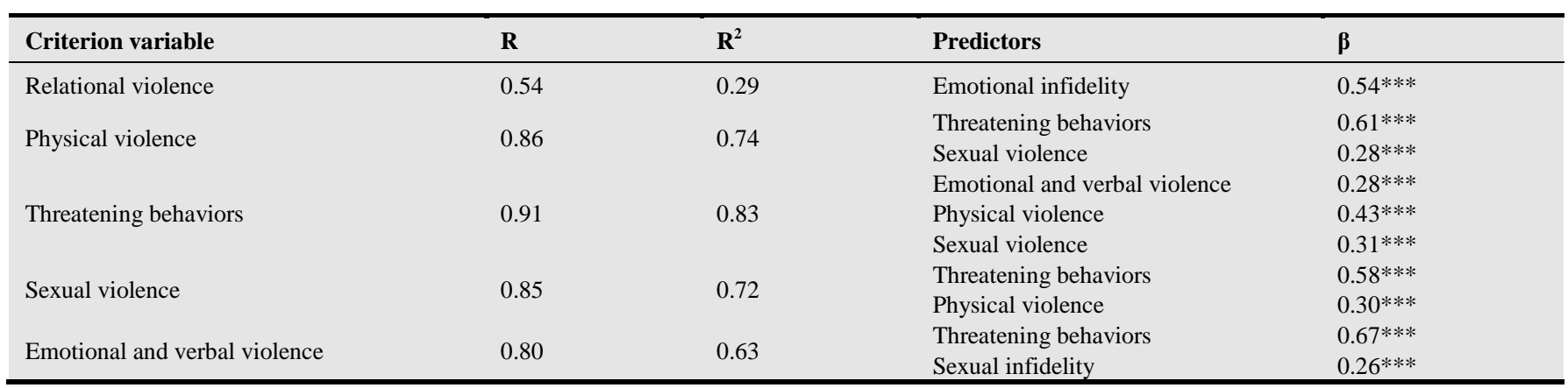

Note: $\mathrm{R}$ multiple correlation; $\mathrm{R}^{2}$ multiple correlation squared; $\beta$ standardized regression coefficient; $* * * \mathrm{p}<0.001$

\section{Discussion}

Research on testing the relationship between jealousy and violence, as well as examining the influence of situational and a background factor in violent behaviour is relatively rare. So the aim of this study was to investigate gender differences in the frequency of violent behaviour and the intensity of jealousy. Furthermore, this study examined potential risk factors for committing and being exposed to dating violence. The results of this study showed that young men were more frequently physically abused by their partner compared to young women. No statistically significant differences in committing physical violence regarding gender were obtained. The results are consistent with numerous studies conducted so far (32-33, 51-52). Research studies emphasize that violence by women is rarely followed by physical injury and mostly includes some mild forms of physical violence. With respect to serious physical injuries, the probability is higher for women compared to men (34). Wolf et al. (31) also found significant gender differences in committing physical violence. According to the authors, women were more frequently perpetrators of physical violence compared to men in all age periods. However, the prevalence of physical perpetration between genders begins to decline in late adolescence. As a result, the differences obtained are no more significant. It is possible that women far more than men use physical violence due to gender differences in negotiation styles. Research revealed that men and women alike use different strategies in expressing their needs, wants and desires. Men tend to use strategies that are more direct, such as asking questions, stating or discussing about their needs and desires (53). Females are more likely than males to rely on indirect strategies related to allusion and withdrawal (54). Indirect strategies, compared to direct, are less effective in achieving goals, in other words getting what the person wants from their partner (55). Scanzoni and Polonko (56) state that indirect negotiation strategies are not effective, because people become frustrated which results in the use of coercive strategies such as indirect aggression or psychological aggression, or even in open aggression such as physical violence. According to this study, it can be concluded that women use violence in situations of frustration as a type of communication, when they determine that all other strategies are shown to be useless.

The results of our study showed that men were more likely to be perpetrators of sexual violence in dating relationships compared to women (63\% of men compared to $22 \%$ of women). However, men state that they are more frequently abused with sexual violence by their partners (51\% of men compared to $24 \%$ of women). The results obtained indicate a significant prevalence of sexual violence, as well as other 
forms of violence, in dating relationships in the area of Bosnia and Herzegovina. The obtained prevalence of sexual violence is higher than that found in other countries (57-60). The prevalence of sexual violence in other countries ranges from $3 \%$ to $37 \%$ in men, as well as between $2 \%$ to $24 \%$ in women.

According to the above-mentioned studies, $14 \%$ to $43 \%$ of women, and $0.3 \%$ to $36 \%$ of men reported that they were victims of sexual violence in dating relationships. Aside from the higher prevalence of sexual violence so far obtained compared to conducted study, the unexpected result was that higher sexual violence was obtained in men compared to women. Some previous studies (61) found that men are more often perpetrators than victims of sexual violence. However, women are those who are exposed to this form of violence in dating relationships. These results could highlight monitoring changes over time, in which women are now committing as well as experience sexual violence to the same level or even more than men. The presence of less traditional nurturing in the younger population could contribute to this change. A growing trend of promoting assertive behaviours and self-promotion in women, as well as the same initiative for taking the "first step" for men and women could contribute to more aggressive behaviour in women during the relationship. One possible cause of aggressive behaviour in women could be changes reflected in more open attitudes about their sexuality (62).

With regard to the results of psychological violence in dating violence, it was found that men are significantly more exposed to threatening behaviour, emotional and verbal violence, compared to women. Some earlier studies noted higher female, than male, aggression which is expressed in indirect aggressive tendencies (63-64). The obtained differences may be a reflection of the earlier described gender differences in negotiation strategies. Women who have endured conflict situations are more likely to avoid physical violence due to the perceived differences in physical strength. Regarding physical abuse, women are more often perpetrators of this form of violence, regardless of their age.

However, if we consider the self-assessment results of psychological violence perpetration, it is evident that there are no significant gender differences in the perpetration of relational, emotional and verbal violence. Only significant gender differences were obtained for threatening behaviour where men, compared to women, were more prone to committing this form of violence. It is possible that psychological aggression in women may be driven by emotional excitement and therefore not perceived as aggressive or abusive behaviour. In accordance with this, they do not report a higher incidence of this form of violence compared to men. In other words, attitudes that justify this type of violence, as well as not a lack of awareness of the harmfulness of this behaviour could contribute to the lower reporting of psychological violence toward their partners (6566). Evolutionary psychologists argue that there are sex differences in jealousy, whereby men tend to be more jealous with respect to the sexual infidelity of partner, while women to emotional infidelity (67-68). In contrast, Harris (69) notes that these differences are not confirmed in most of the studies that have been conducted in this area.

DeWeerth and Kalma (70) noted that women score higher than men in the reported likelihood of physical and verbal abuse of their partner in a case of sexual infidelity. Moreover, two additional studies reported that male and female students who have had an experience of infidelity did not have significant differences in the impact of the sexual infidelity on their sexual relationship (71), or even in their orientation to the sexual and emotional aspects of infidelity (69). In accordance with Harris's (69) findings, the results obtained in this study also did not find any gender differences in the intensity of jealousy in hypothetical situations of sexual and emotional infidelity. So far studies conducted have revealed that jealousy is not an emotion that is a source of stress, but an emotion related to aggressive behaviour. The same was confirmed in our study. An analysis of the regression results showed that jealousy to sexual infidelity significantly predicts the perpetration and exposure to relational, emotional and verbal abuse. This result, as well as those of earlier studies, reported that jealousy is a frequent source of dissatisfaction in intimate partner relationships or relational abuse. Although some earlier studies identified jealousy as a significant risk factor for hostile, aggressive and violent behaviour toward a partner (70, 72-74), the results of our study did not confirm the predictive value of jealousy for physical forms of violence. However, it was found that jealousy significantly contributed to psychological forms of violence. The results of this study indicated that the perpetration of certain forms of violence is a significant risk factor for the perpetration of other forms of violent behaviour toward their partner. More accurately, results revealed that people exposed to one form of violence are at a higher risk of being exposed to other forms of violence in partner relationships. The results obtained confirmed the results of studies suggesting that women who had experience of one type of violence are more likely to experience a variety of other forms of violence from their partners (75).

Exposure to threatening behaviours, in this study, was found to be a statistically significant predictor of exposure to physical, emotional, verbal and sexual abuse by a partner. The results support the findings of studies that revealed a strong relationship between psychological and physical abuse in intimate dating relationships $(8,19)$.

As evident from the obtained results, threatening behaviours, as a form of psychological abuse, are a significant predictor of other forms of violence, which is in accordance with the assumption of psychological aggression as a possible precursor to other forms of violence in dating relationships (18). However, this study used data collected through a transversal design which does not allow us the confidence to conclude that psychological aggression is a precursor of other forms of violence.

According to our results, sexual violence was a statistically significant predictor of physical violence and threatening behaviour. Furthermore, physical abuse was a statistically significant predictor of sexual violence and threatening behaviour. The same relationship was obtained in the study by 
Munoz Rivas et al. (59). The relationships obtained ranged from 0.70 to 0.50 , for both men and women. The results have an important impact on prevention programmes of violence in dating relationships since they refer to the fact that the presence of one form of aggressive behaviour, especially violent behaviour which aims to control a partner, represents a significant risk factor for other forms of violent behaviour (76). Regression analyses on the committing of violence also indicated a relationship between perpetrations of different forms of violence. Threatening behaviours toward the victim were significant risk factors of physical and emotional violence toward a partner. Physical violence was a risk factor for sexual violence and threatening behaviour, while sexual violence significantly contributed to physical violence. These results are in accordance with some earlier studies. In studies conducted on a married couple, the perpetration of physical and psychological victimization significantly contributed to the perpetration of sexual violence (19). Frieze (20) also found a relationship between physical and sexual violence in married women. Similar results were obtained by Meyer et al. (77) in a study conducted on couples involved in marital therapy. The authors found that the wife's assessments of sexual abuse by her partner were significantly related to those of exposure to psychological, physical and physical aggression toward partners. The relationship obtained between the different forms of violence, whether they refer to the perpetration or exposure to violence significantly indicates an overlap between different forms of violence. A person exposed to one form of violence is more likely to experience some other forms of exposure or perpetration of intimate dating violence. Therefore, professionals involved in the prevention of dating violence should, in a situation of exposure to one form of violence, consider the possibility of risk of other forms of victimization. Although this study did not directly test the assumption of the situational-background model of Riggis and O'Leary (48), some of these assumptions were confirmed by the results obtained. However, on the one side, jealousy as a contextual or background variable, and on the other earlier exposure to violence as a situational variable were significant risk factors for perpetration and exposure to violence. Future studies should examine the influence of others background variables (family characteristics, attitude towards violence, personality traits) and situational variables (stress, alcohol consumption) predicted by the model.

The limitations to this study with respect to making valid inferences are related to the sample in question, which is not representative and does not necessary reflect the same prevalence of dating violence as in the general population. However, the prevalence and relationship between the examined variables are in accordance with the studies conducted so far in our country, as well as across the world. Another significant limitation of these studies is the fact that they are mostly based on self-assessment measures. The experience of dating violence is assessed by self-report. However, other alternative methods of measuring dating violence also have limitations, which are even higher. In studies of violence witnesses are rarely present, adolescents often avoid talking to other persons about their experiences of victimization or their perpetration of violence, and it is quite rare for perpetrators of violence to be prosecuted by judicial authorities or to appear in the police system (78).

\section{Conclusion}

The results of this study indicated a high prevalence of dating violence among young people. The obtained results have implications for preventive programmes which should be focused on raising knowledge regarding partners' behaviour in their relationship, abilities to stand up one's self, as well as the possibility of identifying violent behaviour and to adequately respond to violence. Such programmes should be sensitive to gender differences, and particularly focused on the education of young men and women in areas where they have less knowledge about this theme as well as less skills for the constructive resolution of conflicts in dating relationships. The obtained relationship between significant forms of violence, whether it refers to the perpetration or exposure to violence, in this study suggests a significant overlap between different forms of violence. By studying only one form of partner violence we are not able to completely understand intimate dating violence, determine the consequences of such experiences or even provide proper help to victims or perpetrators of violence. Furthermore, this study revealed the contextual variable of jealousy and the situational variable of earlier violence as significant predictors of perpetration and exposure to dating violence. Future studies should take this into account and other variables of violence postulated by the background-situational model of aggression.

\section{References}

[1] E. Miller, J. Breslau, W. J. Chung, J. G. Green, K. A., McLaughlin, and R. C. Kessler, "Adverse childhood experiences and risk of physical violence in adolescent dating relationships,"J. Epidemiol. Community. Health. vol 65, pp. 1006-1013, November 2011.

[2] B. G. Taylor, N. Stein, and F. F. Burden, "Exploring gender differences in dating violence/harassment prevention programming in middle schools: results from a randomized experiment," J. Exp. Criminol. vol 6(4), pp. 419-445, July 2010.

[3] M. O'Keefe, "Teen dating violence: A Review of risk factors and prevention efforts," VAWnet: The National Online Resource Center on Violence Against Women.

[4] L. E. Saltzman, J. L. Fanslow, P. M. McMahon, and G. A. Shelley, Intimate partner violence surveillance: uniform definitions and recommended data elements, Atlanta (GA): Centers for Disease Control and Prevention, National Center for Injury Prevention and Control, 2002.

[5] P. J. Burke, J. E. Stets, and M. A. Pirog-Good, M.A, "Gender identity, self-esteem, and physical and sexual abuse in dating relationships," Soc. Psychol. Q. vol. 51, pp. 272-285, September 1988. 
[6] C. M. Murphy, and S. A. Hoover, "Measuring emotional abuse in dating relationships as a multifactorial construct," in Psychological abuse in violent domestic relations, D. K. Leary and D. R. Maiuro, Eds. New York, NY: Springer Publishing Co, Inc., 2001, pp. 29-46

[7] M. A. Straus and R. J. Gelles, "Societal change and change in gamily violence from 1975 to 1985 as revealed by two national surveys,’J. Marriage. Fam. vol. 48, pp. 465-479, August 1986.

[8] K. C. Basile, I. Arias, S. Desai, and M. P. Thompson, "The differential association of intimate partner physical, sexual, psychological, and stalking violence and posttraumatic stress symptoms in a nationally representative sample of women,'J. Trauma. Stress, vol.17, pp. 413-421, October, 2004.

[9] A. L. Coker, R. E. McKeown, M. Sanderson, K. Davis, R. F: Valois, and S. Huebner, "Severe dating violence and quality of life among South Carolina high school students,". Am. J. Prev. Med. vol. 19, pp. 220-227, November 2000.

[10] C. Garcia-Moreno, H. A. Jansen, M. Ellsberg, L. Heise, L., and C $\mathrm{H}$. Watts, "Prevalence of intimate partner violence: findings from the WHO multi-country study on women's health and domestic violence," Lancet, vol. 368, ppt. 1260-1269, October 2006.

[11] C. R. Hanneke, N. M. Shields, and G. J. McCall, "Assessing the prevalence of marital rape," J. Interpers. Violence. vol. 1, pp. 350-362, September 1986.

[12] L. L. Marshall, "Psychological abuse of women: six distinct clusters," J. Fam. Violence. vol. 11, pp. 379-409, December 1996.

[13] J. Monnier, H. S. Resnick, D. G. Kilpatrick, and B. Seals, "The relationship between distress and resource loss following rape," Violence. Victm. vol. 17, pp. 85-91, February 2002.

[14] J. Raiford, G. Wingood, and R. Diclemente, "Prevalence, incidence, and predictors of dating violence: A longitudinal study of African American female adolescents," J. Womens. Health. vol. 16, str. 822-832, August 2007.

[15] R. S. Thompson, A. E. Bonomi, R. J. Anderson, R. J. Reid, J. A., Dimer, D. D. Carrell, and F. P. Rivara, "Intimate Partner Violence: Prevalence, Types, and Chronicity in Adult Women," Am. J. Prev. Med. vol. 30, pp. 447-57, June 2006.

[16] K. D. O'Leary and A. M. S. Slep, "A dyadic longitudinal model of adolescent dating aggression," J. Clin. Child. Psychology. vol 32, pp. 314-327, September 2003.

[17] D. J. Whitaker, T. Haileyesus, M. Swahn, L. S. Saltzman, "Differences in frequency of violence and report injury between relationships with reciprocal and nonreciprocal intimate partner violence," Am. J. Public. Health, vol. 97, pp. 941-947, May 2007.

[18] C. M. Murphy and K. D. O’Leary, "Psychological aggression predicts physical aggression in early marriage," J. Consul. Clin. Psych. vol. 57, pp. 579-582, October 1989.

[19] A. D. Marshall and A. Holtzworth-Munroe, "Varying forms of husband sexual aggression: predictors and subgroup differences," J. Fam. Violence, vol. 16, pp. 286-296, September 2002.

[20] I. H. Frieze, "Investigating the causes and consequences of marital rape" Signs. vol. 8, pp. 532-553, Ferbruary, 1983.

[21] F. A. Rodenburg and J. W. Fantuzzo, "The measure of wife abuse: steps toward the technique," J. Fam. Violence. vol. 8, ppt. 203-228, September 1993.

[22] M. A. Straus, S. L. Hamby, S. BoneyMcCoy, and D. B. Sugarman, "The revised Conflict Tactics Scales (CTS2)—Development and preliminary psychometric data,” J. Fam. Issues. vol. 17, pp. 283-316, May 1996.

[23] P. C. Giordano, D. A. Soto, W. D. Manning, and M. A. Longmore, "The characteristics of romantic relationships associated with teen dating violence," Soc. Sci. Res. vol. 39, pp. 863-874, November 2010.

[24] V. M. Herrera, J. D. Wiersma, and H. H. Cleveland, "The influence of individual and partner characteristics on the perpetration of intimate partner violence in young adult relationships," J. Youth Adolescence. vol. 37, pp. 284-296, March 2008.

[25] M. A. Straus, "Dominance and symmetry in partner violence by male and female university students in 32 nations," Child. Youth. Serv. Rev. vol. 30, pp. 252-275, October 2008.

[26] M. A. Straus, M. A. and I. L. Ramirez, "Gender symmetry in prevalence, severity, and chronicity of physical aggression against dating partners by University students in Mexico and USA,” Aggressive Behav. vol. 33, pp. 281-290, August 2007.

[27] S. L. Williams and I. H. Frieze, "Patterns of violent relationships, psychological distress, and marital satisfaction in a national sample of men and women," Sex. Roles. vol. 52, pp. 771-784, June 2005.

[28] H. Gray and V. Foshee,"Adolescent dating violence: Differences between one-sided and mutually violent profiles,“ J. Intepers. Violence. vol. 12, pp. 126-141, February 1997.

[29] S. F. Lewis and W. Fremouw, "Dating violence: A critical review of the literature," Clin. Psychol. Rev. vol. 21, pp. 105-127, February 2001.

[30] 30 J. Connolly and W. Josephson, "Aggression in adolescent dating relationships: Predictors and prevention," Prev. Res. vol. 14, pp. 3-5, December 2007.

[31] D. A. Wolfe, C. Wekerle,, K. Scott, A. Straatman, C. Grasley, and D. Reitzel-Jaffe, "Dating violence prevention with at-risk youth: A controlled outcome evaluation," J. Consult. Clin. Psychol. vol. 71, pp. 279-291, April 2003.

[32] V. A. Foshee and R. Matthew, "Adolescent dating abuse perpetration: A review of findings, methodological limitations, and suggestions for future research," in The Cambridge handbook of violent behavior and aggression, D. Flannery, A. Vazonsyi, and I. Waldman, Eds. New York: Cambridge University Press, 2007, pp. 431-449.

[33] M. J. Muñoz-Rivas, J. L. Graña, K. D. O’Leary, and M. P. González,"Physical and psychological aggression in dating relationships in Spanish university students," Psicothema. vol. 19, pp. 102-107, February 2007a.

[34] M. J. Muñoz-Rivas, J. L. Graña, K. D. O'Leary, and M. P. González,"Aggression in adolescent dating relationships: prevalence, justification and health consequences," J. Adolescent. Health. vol. 40, pp. 298-304, Ferbruary 2007b

[35] E. L. Lichter and L. A. McCloskey,"The effects of childhood exposure to marital violence on adolescent gender-role beliefs and dating violence," Psychol. Women. Quart.vol. 28, pp. 344-357, November 2004. 
[36] S. Kaura and B. Lohman, "Dating violence victimization, relationship satisfaction, mental health problems, and acceptability of violence: A comparison of men and women, " $J$. Fam. Violence.vol. 22, pp. 367-368, August 2007.

[37] S. H. Chiffriller and J. J. Hennessy,"Male batterer profiles: Support for an empirically-generated typology, "J. Offender. Rehabil. vol. 44, pp. 117-131, September 2007.

[38] C. R. Harris,"A review of sex differences in sexual jealousy, including self-report data, psychophysiological responses, interpersonal violence, and morbid jealousy. Pers. Soc. Psychol. Rev.vol. 7, pp. 102-128, May 2003.

[39] L. K. Guerrero and P. A. Andersen,“ Jealousy experience and expression in romantic relationships," in Handbook of communication and emotion, P. A. Andersen and L. K. Guerrero, Eds. San Diego, CA: Academic Press, 1998, pp. 155-188.

[40] D. M. Buss, "Sexual Jealousy,“ Psychol. Topics. vol. 22, pp. 155-182, July 2013.

[41] D. M. Buss and M. Haselton,"The evolution of jealousy. Trend sin Cognitive Sciences,“ vol. 9, pp. 506-507, November 2005.

[42] L. K. Guerrero and A. M. Chavez,"Relational Maintance in Cross-Seks Friendships Characterized by Different Types of Romantic Intent: An Exploratory Study. Western. J. Comm., vol. 69, pp. 339-358, February 2005.

[43] C. A. Smith and R. S. Lazarus," Emotion and adaptation,“ in Handbook of personality theory and research, L. A. Pervin, Ed. New York: Guilford, 1990, pp. 609-637.

[44] J. P. Dillard, J. P. "The role of affect in communication, biology, and social relationships," in Handbook of communication and emotion: Research, theory, applications, and contexts, P. A. Andersen and L. K. Guerrero, Eds. New York: Academic Press 1998, pp. xvii-xxxii.

[45] G. L. White and P. E. Mullen, "Jealousy: Theory, research and clinical strategies,"New York: Guilford Press, 1989.

[46] S. Planalp, V. L. DeFrancisco, D. Rutherford,"Varieties of Cues to Emotion in Naturally Occuring Settings," Cognition. Emotion. vol. 10, pp. 137-153, September 1996.

[47] J. B. Bryson,"Modes of response to jealousy-evoking situations, " in The psychology of jealousy and envy, P. Salovey, Ed. NY: Guilford Press, 1991, pp. 178-205.

[48] D. S. Riggs and K. D. O'Leary,“ A theoretical model of courtship aggression,“ in Violence in dating relationships: Emerging social issues, M. A. Pirog-Good and J. E. Stets, Eds. New York: Praeger, 1989, pp. 53-70.

[49] M. A. Straus, S. L. Hamby and W. L. Warren,"The Conflict Tactics Scales Handbook,“ Western Psychological Services, Los Angeles, CA. 2003.

[50] I. Pavela and N. Šimić,“ Razlike u ljubomori između muškaraca i žena: provjera evolucijske hipoteze i hipoteze uvjerenja," Psychol. Topics. vol. 21, pp. 105-120, May 2012.

[51] V. A. Foshee, H. L. Reyes and S. C. Wyckoff, “Approaches to preventing psychological, physical, and sexual partner abuse," in Understanding psychological and physical aggression in couples: Existing evidence and clinical implications, D. O'Leary and E. Woodin, Eds. Washington, D.C.: American Psychological Association, 2009.
[52] K. D. O'Leary, A. M. S. Slep, M. Cascardi and S. Avery-Leaf,"Gender differences in dating aggression among multiethnic high school students,“ J. Adolescent. Health. vol. 42, pp. 473-479, February 2008.

[53] T. Falbo and L. A. Peplau,"Power strategies in intimate relationships,“ J. Pers. Soc. Psychol. vol.38, pp. 618-628. May 1980.

[54] T. Falbo,"PAQ styles and power strategies used in intimate relationships,“ Psychol. Women. Quar. vol. 6, pp. 399-405, December 1982.

[55] S. Lloyd,"Conflict in premarital relationships: Differential perceptions of males and females,"Fam. Relat. vol. 36, pp. 290-294, July 1987.

[56] J. Scanzoni, J. and K. Polonko,"A conceptual approach to explicit marital negotiation,“ J. Marriage. Fam. vol. 42, pp. 31-44, Ferbruary 1980

[57] L. J. Hickman, L. H. Jaycox, J. Aronoff, "Dating violence among adolescents. Prevalence, Gender distributions, and Prevention Program Effectiveness, "Trauma. Violence. Abus. vol. 5, pp. 123-142, Appril 2004.

[58] C. E. Molidor, R. M. Tolman, and J. Koeber,"Dating can be hazardous to a teen's health: Exploring the darker side of adolescent romantic relationships," Prevent. Research., Summer,1-5, 2000.

[59] M. J. Muñoz-Rivas, J. L. Graña, K. D. O’Leary, and M. P. González, "Prevalence and predictors of sexual aggression in dating relationships of adolescents and young adults," Psicothema. vol. 21, pp. 234-240, May 2009.

[60] D. A. Wolfe, K. Scott, C. Wekerle, and A. L: Pittman,"Child maltreatment: Risk of Adjustment Problems and Dating Violence in Adolescence,"“ J. Am. Acad. Child. Adolesc. Psychiatry. vol. 40, March 2001.

[61] J. Archer,"Sex differences in aggression between heterosexual partners: A meta-analytic review," Psychol. Bull. vol. 126, pp. 651-680, September 2000.

[62] D. Ajduković, A. Löw, and N. Sušac, "Rodne razlike i prediktori partnerskog nasilja u mladenačkim vezama "Ljetop. Soc. Rada. vol 18, pp. 527-553, December 2011.

[63] M. S. Harned,"Abused women or abused men? An examination of the context and outcomes of dating violence,"Violence Vict. vol. 16, pp. 269-285, June 2001.

[64] L. Owens, R. Shute, and P. T. Slee, "Boys aggression to girls: The views of Year 9 girls, boys and their teachers," in Contemporary Research on Aggression, vol. I, K. Osterman and K. Bjorkqvist, Eds. School Violence, 2006 [Proceedings of the 16th World Meeting of the International Society for Research on Aggression Greece, 2006].

[65] J. Bookwala, I. H. Frieze, C. Smith, and K. Ryan, "Predictors of dating violence: A multivariate analysis," Violence. Vict. vol. 7, pp. 297-311, February 1992.

[66] M. Schwartz, S. G. O’Leary, and K. T. Kendziora,"Dating aggression among high school students," Violence. Vict. vol. 12, 295-305, January 1997.

[67] R. L. Michalski and T. Schackelford, "Evolutionary personality psychology: Reconciling human nature and individual differences, "Pers. Indiv. Differ. vol. 48, pp. 509-516, February 2010. 
[68] D. M. Buss, R. J. Larsen, D. Westen, and J. Semmeiroth, “Sex differences in jealousy. Evolution, physiology and psychology,“ Psychol. Sci. vol. 3, pp. 251-255, January 1992.

[69] C. R. Harris,"Psychophysiological responses to imagined infidelity: The specific innate modular view of jealousy reconsidered,“ J. Pers. Soc. Psychol. vol. 7S, pp. 1082-1091, June 2000.

[70] C. De Weerth, C and A. P. Kalma,"Female aggression as a response to sexual jealousy: A sex role reversal?," Aggressive Behav. vol. 19, pp. 265-279, February 1993.

[71] G. L. Hansen,"Extradyadic relations during courtship,“ J. Sex. Res. vol. 23, pp. 382 - 390, January 1987.

[72] P. A. Andersen, S. V. Eloy, L. K. Guerrero, and B. H. Spitzberg,"Romantic jealousy and relational satisfaction: A look at the impact of jealousy experience and expression,“ Commun. Rep. vol. 8, pp. 77-85, January 1995.

[73] L. K. Guerrero, B. H. Spitzberg, and S. M. Yoshimura, “ Sexual and emotional jealousy," in The handbook of sexuality in close relationships J. Harvey, A. Wenzel and S. Sprecher, Eds.
Mahwah, NJ: Lawrence Erlbaum Associates, 2004, pp. 311-345.

[74] T. K. Shackelford,"Self-esteem in marriage," Pers. Indiv. Differ. vol.30, pp. 371-390, November 2001.

[75] C. Krebs, M. J. Breiding, A. Browne, T. Warner,"The association between different types of intimate partner violence experienced by women, “ J. Fam. Violence. vol. 26, pp. 487-500. August 2011

[76] D. R. Follingstad, R. G. Bradley, C. M. Helff, J. E. Laughlin,“A model for predicting dating violence: Anxious attachment, angry temperament, and need for relationship control,“Violence. Vict. vol. 17, pp. 35-47, February 2002.

[77] S. Meyer, D. Vivian and K. D. O'Leary,"Men's sexual aggression in marriage: couples' reports," Violence. Against. Wom. vol. 4, pp. 415-435, August 1998.

[78] V. Foshee, K. E. Bauman, X. B. Arriaga, R. W. Helms, G. G. Koch, and G. F. Linder,"An evaluation of safe dates, an adolescent dating violence prevention program, “Am. J. Public. Health. vol. 88, pp. 45-50, January 1998. 